\title{
The effect of age at time of cochlear implantation on the pragmatic development of the prelingual hearing impaired children
}

\author{
Mona Sameeh Khodeir ${ }^{1 *}$ D, Dina Fouad El Sayed Moussa² and Rasha Mohammed Shoeib ${ }^{1}$
}

\begin{abstract}
Background: Pragmatics is the social use of language that draws on understanding human interactions in specific contexts and requires engagement with a communicative partner or partners. The hearing-impaired children are known to have a pragmatic language delay as hearing impairment deprived of exposure to natural communication interactions, in addition to the language delay they have. Since the age of implantation has emerged as an important predictor of language, hearing, and speech in children who use cochlear implants (Cl), question aroused about the benefits of early cochlear implantation on pragmatic language development in those children. Thus, this study aims to compare the pragmatic language development of the prelingual hearing impaired children who cochlear implanted before the age of 3 years and those who cochlear implanted after the age of 3 years.
\end{abstract}

Results: The two study groups showed no significant differences regard their scores in the Egyptian Arabic Pragmatic Language Test (EAPLT). The two studied groups had pragmatic language scores below their 5th percentile. Among the studied groups, the scores of the EAPLT were positively correlated to the age of the children, the children's language abilities, and the duration of the received language rehabilitation, with no significant correlation to the age of implantation.

Conclusions: The age of implantation has no impact on pragmatic language development in children with $\mathrm{Cl}$. The prelingual children with $\mathrm{Cl}$ are susceptible to delays in the pragmatic language development that is primarily related to the age of those children and their language abilities, besides their experience in social interactions. These results should be considered in their rehabilitative plan and advocate the importance of early incorporation of pragmatic behaviors into their intervention programs.

Keywords: Cochlear implant, Pragmatic language, Hearing impairment

\section{Background}

With the evolution of the cochlear implantation (CI) technique, children with hearing impairment had shown significant improvements in comprehension and expression of spoken language over the first 3 years of implant

\footnotetext{
* Correspondence: mona.khodeir@med.asu.edu.eg;

dr.mona.khodair@gmail.com

'Unit of Phoniatrics, Otorhinolaryngology Department, Faculty of Medicine, Ain Shams University, Abbassia, Lotfy Elsayed Street, Cairo 11566, Egypt Full list of author information is available at the end of the article
}

use [1]. Over the last decade, cochlear implants showed a great evolution in their speech processing technology and hardware [2]. Along with the decrease in the average age at cochlear implantation, language and speech outcomes have further improved for children with $\mathrm{CI}$ such that some children now acquire spoken language as do children with mild to moderate hearing loss [3]. Some studies reported that infants and toddlers who receive implants show rapid improvements in auditory skills during the first year of device use irrespective of age at 
implantation. Moreover, younger children with CI could acquire auditory skills closer to those of their peers with normal hearing [4].

While studying the effect of $\mathrm{CI}$ on language development, researchers have focused on three essential elements of language, phonology, semantics, and syntax. Upon that, a model of central auditory nervous system flexibility is established to present the time frame for critical/sensitive periods of language development. This model indicated that there is a time-dependent series of functions in a sequence that is based on responsive adaptations made by the central nervous system to psychophysical and electrophysiological stimuli. Accordingly, it is hypothesized that the critical/sensitive period of phonology occurs between the 6th month of fetal life till the end of the 1st year of a child's life. Also, the critical/sensitive periods for syntax runs through the 4th year of life, and for semantics, it is through the 15th or 16th year of life [5].

Much of the recent research in pediatric cochlear implants (CIs) started to focus on studying the use of pragmatic communication behaviors by children with sensorineural hearing loss (SNHL). These studies have suggested that pragmatic language ability is less developed in deaf and hearing-impaired children as both the quality and quantity of their daily face-to-face discourses are reduced [6]. These different or less effective pragmatic abilities of children with SNHL may be explained by less flexible use of language structures, difficulties in the theory of mind, difficulties in auditory perception of spoken language, and less exposure to varied pragmatic situations and strategies. Therefore, children with SNHL have more incidents of inappropriate use of the different abilities, compared to hearing children [7]. Regarding the pragmatic ability to take turns during a conversation, children with SNHL are less skilled at maintaining a conversation topic, use more instructions and fewer questions, and show less clear pragmatic communication functions as a result of the language delay of the children with hearing loss $[8,9]$.

Although CI may provide deaf and hearing-impaired children with a good opportunity to develop language skills, those children will remain have difficulties in their early social experiences and interaction mediated by language [10]. This is because SNHL in early childhood leads to immature or delayed social communication due to an early lack of exposure, among other factors. This in turn will not allow children to appropriately communicate and form peer relationships due to their limited use of common conversational strategies [7].

Despite that, there is still a conflict and incomplete evidence regarding the benefits of early implantation on language and speech development $[11,12]$. Over the past 10 years, many authors have demonstrated that the results of language outcome, speech production, and understanding in children implanted at under 24 months of age were significantly better than for children implanted later $[12,13]$. While older age at $\mathrm{CI}$ is associated with greater gaps between chronological and language age [1]. One of these studies was that by Rinaldi et al. [10] who compared the linguistic skills of children implanted by 12 months of age with children implanted between 13 and 26 months of age. Authors reported that despite the strong relationship among lexical, grammar, and pragmatic skills, the delays found for grammar and pragmatic skills were greater than expected based on the vocabulary size. The authors reported also that these delays were based primarily on the age of diagnosing of SHNL, and not the age of CI.

Meanwhile, studies are concerned more with studying the impact of age of $\mathrm{CI}$ on the development of the auditory skills, language achievement as a whole, with limited research that focuses on the impact of age of $\mathrm{CI}$ on pragmatic understanding and development in children with SHNL. The importance of studying the use of pragmatic communication behaviors by children with SNHL and its relation to the age of $\mathrm{CI}$ is that it provides important supplemental information for decisions regarding the appropriate age of CI [14]. Moreover, it allows a basis for understanding the implications of therapy intervention that improves the pragmatic skills of these children [15].

Consequently, the purpose of this study is to compare the pragmatic language development among children with prelingual SNHL who cochlear implanted before the age of 3 years and those who cochlear implanted after the age of 3 years. This study aims to investigate the impact of early cochlear implantation on the development of the pragmatic language of those children.

\section{Methods \\ Participants}

This study was applied to 60 Arabic-speaking Egyptian children between 4 and 7 years, 4 months. The selected children were diagnosed to have pre-lingual bilateral severe to profound SHNL and have within normal auditory level by the cochlearly aided audiogram. All children were cochlear implanted and received auditory training and language rehabilitation for at least 6 months after the cochlear implantation. As for the age of cochlear implantation, the selected children were divided into two groups: group I included 30 children who were cochlear implanted before the age of 3 years old, and group II included children who were cochlear implanted after the age of 3 years old. All children had an average IQ and normal mental age as assessed by Stanford-Binet intelligence scale, Arabic Version (5th edition) [16]. Children with syndromic SNHL were excluded. 
Informed written consent was obtained from parents of the participated children before enrollment in this study and the study protocol has been approved by the Ethical Committee of Human Research.

Method:

The selected children passed through the protocol of assessment of the hearing-impaired children which is applied at the Phoniatrics Unit [17] as follows:

\section{Elementary diagnostic procedures}

1. Child and parent interview that involved history of the cause, onset, course, and duration of the prelingual SNHL, and its degree. It also includes the developmental history of the child, the age at which the hearing aids (HAs) were provided, the age of the $\mathrm{CI}$, laterality of the CIs, and the age at which the auditory training and language rehabilitation therapy began before and after CI, and its duration.

2. Clinical examination of the children that includes a general examination to exclude features of any dysmorphic syndromes and visual assessment of aural-oral tract.

\section{Clinical diagnostic aids}

1. Cochlearly aided audiometry: it checks the auditory level of the participated children by their CI and allows to select of children who have an auditory level within the normal range.

2. Language evaluation using the Modified Preschool Language Scale-4th edition (PLS-4), the Arabic version [18]: it assesses the language development of the child and provides 3 language ages: the receptive, expressive, and total language ages according to child's response to the test items.

3. Pragmatic language assessment using the Standardized Egyptian Arabic Pragmatic Language Test "EAPLT" [19]. It assesses nonverbal, paralinguistic, and verbal skills. Depending on the child's chronological age, the 5th and 95th percentile ranks of the child's total score and his/ her scores in each subset of the EAPLT were calculated. The 5 th percentile rank indicates that the child developed the skill, whereas the 95th percentile rank implies that the child mastered it. Scores below the fifth percentile rank indicated pragmatic language delay.

\section{Data management and analysis}

The data were statistically analyzed with the Statistical Package for Social Science under windows version 24 . Mean and standard deviation values were used to describe the data. The paired $t$ test and chi-square test were used to compare the chronological age, gender, and mental abilities (IQ and mental age) of the two studied groups to ensure that are the 2 groups were matched (significant $p$ value at $<0.05$ ). The paired $t$ test was used to compare the mean of the receptive, expressive, and total language ages by the modified PLS-4 (Arabic version) among the two studied groups (significant $p$ value at $<0.05)$. It was also used to compare the mean of the total score and the scores of each subset of EAPLT among the two studied groups, with a significant $p$ value at $<0.05$. Pearson correlation coefficient was used to correlate the total score of the Egyptian Arabic Pragmatic Language Test (EAPLT) of the participated children in the two studied groups to their chronological age, age of $\mathrm{CI}$, duration of the received language rehabilitation. It was also used to correlate the total score of the Egyptian Arabic Pragmatic Language Test (EAPL $\mathrm{T}$ ) of the participated children in the two studied groups to their receptive, expressive, and total language ages by the modified PLS-4 (Arabic version), with a significant $p$ value at $<0.01$.

\section{Results}

Table 1 shows the demographic data of the participated children. Tests of significance (paired $t$ test and chisquare test) revealed that there was no significant difference between the two studied groups regards their chronological age, sex, and mental abilities indicating that the two studied groups were matched to each other. The medical history taken revealed that the mean age of diagnosis of SNHL was $0.8 \pm 0.37$ in group I (children with CI before the age of 3 years), and $1.9 \pm 0.66$ in group II (children with CI after the age of 3 years). The most common etiological cause of the prelingual SNHL in both groups I and II were congenital causes. Children in groups I and II were fitted by bilateral HAs at the age of $1.39 \pm 0.9$, and $2.28 \pm 1.04$ years, respectively. The mean age of CI was $2.3 \pm 0.62$ years in group I and $4.7 \pm$ 0.74 years in group II. The mean age of starting language rehabilitation, the mean duration of the received language rehabilitation, and the mean age of 1st word/sentence acquisition were reported in Table 2. By comparing the receptive, expressive, and total language ages (by the modified PLS-4, Arabic version) among the two studied groups, no statistical difference was found between children with cochlear implantation before 3 years and those with cochlear implantation after the age of 3 years (Table 3 ).

Results of the EAPLT reported that children in both groups had pragmatic language scores below their 5 th percentile, as well as the pragmatic language age range of children in both groups, which were between 2.1 and $<4$ years (Table 4). While comparing the results of the EAPLT, it was revealed that children in group 1 (with CI 
Table 1 The demographic data of the participated children

\begin{tabular}{|c|c|c|c|c|}
\hline & Prelingual SNHL children $\mathrm{Cl}$ before 3 years & Prelingual SNHL children $\mathrm{Cl}$ after 3 years & Value & $p$ value \\
\hline $\begin{array}{l}\text { The chronological age range } \\
\text { (min.-max.), in years }\end{array}$ & $4.00-7.40$ & $4.50-7.40$ & - & \\
\hline $\begin{array}{l}\text { The chronological age (mean } \pm \\
S D \text { ), in years }\end{array}$ & $5.9 \pm 1.26$ & $6.09 \pm 1.09$ & $t=1.92$ & $0.06^{*}$ \\
\hline IQ $($ mean \pm SD) $* * *$ & $90.2 \pm 7.29$ & $90.5 \pm 6.5$ & $t=1.23$ & $0.23^{*}$ \\
\hline $\begin{array}{l}\text { Mental age }(\text { mean } \pm S D) \text {, in } \\
\text { years*** }\end{array}$ & $5.4 \pm 1.29$ & $5.5 \pm 0.75$ & $t=0.55$ & $0.58^{*}$ \\
\hline \multirow{2}{*}{$\begin{array}{l}\text { Gender } \\
\text { (Number \%) }\end{array}$} & $16(53.3 \%)$ & $18(60 \%)$ & $x^{2}=0.27$ & $0.60^{* *}$ \\
\hline & $14(46.7 \%)$ & $12(40 \%)$ & & \\
\hline
\end{tabular}

*Paired $t$ test, $p$ value significant at $<0.05$

${ }^{*}$ Chi-square test $\left(X^{2}\right) ; p$ value significant at $<0.05$

***IQ ratio and the mental age were the data obtained by the Stanford-Binet intelligence scale, Arabic Version (5th edition) [16]

before the age of 3 years) had relatively higher scores of the EAPLT subsets and total score in comparison to children in group II (with CI after the age of 3 years); however, this difference was statistically insignificant (paired $t$ test; $p$ value significant at $>0.05$ ) (Table 5). Group I showed relatively better conversation skills more than children in group II, but this difference was statistically insignificant (Table 6).
There was a significant positive correlation ( $p$ value significant at $>0.01$ ) between the total score of the EAPLT and the chronological age of the children in groups I and II, duration of the received language rehabilitation, and the receptive, expressive, and total language ages. There was no correlation between the scores of the EAPLT and the age of cochlear implantation (Table 7).

Table 2 Ages at time of diagnosis of SNHL, at time of cochlear implantation, at the time of starting language rehabilitation, etiology of the SNHL, laterality of the implanted ear, ages of acquisition of the 1st word/sentence, duration of the received language rehabilitation

\begin{tabular}{|c|c|c|c|}
\hline & & \multirow{2}{*}{$\begin{array}{l}\text { Group I } \\
(n=30) \\
\text { Prelingual SNHL children Cl before } \\
3 \text { years }\end{array}$} & \multirow{2}{*}{$\begin{array}{l}\text { Group II } \\
(n=30) \\
\text { Prelingual SNHL children } \mathrm{Cl} \text { afte } \\
3 \text { years }\end{array}$} \\
\hline & & & \\
\hline \multicolumn{2}{|c|}{ Age at time of diagnosis of SNHL (mean $\pm S D$ ), in years } & $0.8 \pm 0.37$ & $1.9 \pm 0.66$ \\
\hline \multirow{3}{*}{$\begin{array}{l}\text { Etiology of the SNHL (Number } \\
\%)\end{array}$} & Congenital & $28(93.3)$ & $26(86.7 \%)$ \\
\hline & $\begin{array}{l}\text { Viral (post } \\
\text { meningitis) }\end{array}$ & $0(0 \%)$ & $4(13.4)$ \\
\hline & Ototoxic drugs & $2(6.7 \%)$ & $0(0 \%)$ \\
\hline \multicolumn{2}{|c|}{ Age of bilateral HAs (mean $\pm S D$ ), in years } & $1.39 \pm 0.9$ & $2.28 \pm 1.04$ \\
\hline \multicolumn{2}{|l|}{ Age of $\mathrm{Cl}($ mean $\pm \mathrm{SD})$, in years } & $2.3 \pm 0.62$ & $4.7 \pm 0.74$ \\
\hline \multirow[t]{3}{*}{ The implanted ear (Number \%) } & Right ear & $14(53.3 \%)$ & $16(60 \%)$ \\
\hline & Left ear & $12(40 \%)$ & $14(40 \%)$ \\
\hline & Bilateral ears & $2(6.7 \%)$ & $0(0 \%)$ \\
\hline \multicolumn{2}{|c|}{$\begin{array}{l}\text { No (\%) of children who received language } \\
\text { rehabilitation and fitted with bilateral HAs before } \mathrm{Cl} \text {. }\end{array}$} & 19 (63.4\%), & $26(86.7 \%)$ \\
\hline \multicolumn{2}{|c|}{$\begin{array}{l}\text { Age of starting language rehabilitation (mean } \pm S D) \text {, } \\
\text { in years }\end{array}$} & $1.9 \pm 0.66$ & $2.9 \pm 0.94$ \\
\hline \multicolumn{2}{|c|}{$\begin{array}{l}\text { Duration of the received language rehabilitation } \\
\text { (mean } \pm S D \text { ), in years }\end{array}$} & $4.09 \pm 1.44$ & $\begin{array}{l}4.1 \pm 1.14 \\
t=-0.15(0.583 \mathrm{NS})\end{array}$ \\
\hline \multicolumn{2}{|c|}{$\begin{array}{l}\text { Age at time of acquisition of the } 1^{\text {st }} \text { word (mean } \pm \\
\text { SD), in years }\end{array}$} & $2.9 \pm 1.05$ & $4.1 \pm 2.14$ \\
\hline \multicolumn{2}{|c|}{$\begin{array}{l}\text { The age of acquisition of the } 1 \text { st sentence (mean } \pm \\
\text { SD), in years }\end{array}$} & $3.6 \pm 1.65$ & $5.5 \pm 2.26$ \\
\hline
\end{tabular}


Table 3 Mean and standard deviation (SD) values of the receptive, expressive, and total language ages by the Modified Pre-school Language Scale-4, Arabic version and comparison between their values among the 2 studied groups

\begin{tabular}{llll}
\hline & $\begin{array}{l}\text { Group I } \\
(\boldsymbol{n}=\mathbf{3 0})\end{array}$ & $\begin{array}{l}\text { Group II } \\
(\boldsymbol{n}=\mathbf{3 0})\end{array}$ & $\boldsymbol{p}$ value \\
& $\begin{array}{l}\text { Prelingual SNHL children Cl before } \\
\mathbf{3} \text { years }\end{array}$ & $\begin{array}{l}\text { Prelingual SNHL children Cl after } \\
\mathbf{3} \text { years }\end{array}$ \\
\hline $\begin{array}{l}\text { Receptive language age (mean } \pm \text { SD), in years } \\
\text { Expressive language age (mean } \pm \text { SD), in }\end{array}$ & $3.1 \pm 1.22$ & $2.8 \pm 0.80$ & 0.238 \\
years & $2.7 \pm 0.96$ & $2.5 \pm 0.58$ \\
Total language age (mean \pm SD), in years & $2.9 \pm 1.05$ & $2.6 \pm 0.71$ & 0.115 \\
\hline
\end{tabular}

Paired $t$ test; $p$ value is significant at $<0.05$

\section{Discussion}

Pragmatic language is the most abstract and complex of all language skills which is important for everyday interactions [20]. Pragmatics relates to the rules required to use language appropriately and effectively for social interaction and exchange ideas in different conversational contexts, such as turn-taking in conversation, maintaining and/or changing a topic, adding information, or asking questions [21]. The linguistic skills of children who use CIs show great individual variability, and these skills can be potentially affected by numerous variables, such as the age at diagnosis of hearing loss, a previous usage of the hearing aids, the age at beginning language rehabilitation, and general intellectual skills demonstrating how the plasticity of the child's brain and basic cognitive competence is crucial for learning. Besides, recently the age of cochlear implantation became one of the main factors that impact greatly the auditory, language, and communicative social skills development among children with SHNL who use CI technology [22].

The current study aimed to compare the pragmatic language development of the Egyptian Arabic-speaking children with prelingual SNHL who cochlear implanted before the age of 3 years and those who cochlear implanted after the age of 3 years. Children who participated in this study were selected to be in the same age range (4.1 and 7.4 years), with normal cognitive abilities, and the same degree of hearing loss (severe to profound SNHL), thus, to avoid any bias of the results. The findings of this study revealed that all children who participated in this study had significantly delayed pragmatic language development with no significant statistical difference between the two studied groups regarding their pragmatic language score. This delay in pragmatic language was expected because children with hearing impairment even with the use of CI have difficulties in their interactions with communication partners and their caregivers due to their compromised language skills with a reduced ability to understand how words and structures are used to convey meaning, and reduced ability to be understood. Moreover, exposure to information in their social environment with this delay in language abilities deprives them of social opportunities that could allow them to observe others socially and acquire knowledge as an onlooker. Given these points, explains why hearing-impaired children vulnerable to pragmatic language challenges. This goes with what is mentioned by Mood et al. [23] that pragmatic language development in children depends on three main factors: (1) attending to children's interactions with caregivers and others, (2) supporting the development of the theory of mind through play and use of mental state language, and (3) providing accessible opportunities for social interaction. These factors are all lost in children who participated in this study. The delay of pragmatic skills in children with CI was also reported by Most et al. [8] and Rinaldi et al. [10], and these delays were found to be greater than delays found in lexical skills.

Eventually, the result that the age of implantation had no impact on the development of pragmatic language

Table 4 Ranks of percentile of the total score of the Egyptian Arabic pragmatic language test (EAPLT) and the pragmatic language age range among the 2 studied groups

\begin{tabular}{lll}
\hline & $\begin{array}{l}\text { Group I } \\
(\boldsymbol{n}=\mathbf{3 0})\end{array}$ & $\begin{array}{l}\text { Group II } \\
(\boldsymbol{n}=\mathbf{3 0})\end{array}$ \\
\hline Prelingual SNHL children Cl before 3 years & Prelingual SNHL children Cl after $\mathbf{3}$ years \\
Pragmatic language percentile rank, number (\%) & $5.9 \pm 1.26$ & $6.9 \pm 0.73$ \\
& $\begin{array}{l}30(100 \%) \\
(\text { below the 5th percentile) }\end{array}$ & $\begin{array}{l}30(100 \%) \\
\text { (below the 5th percentile) }\end{array}$ \\
Pragmatic language age range, number of patients \% & $2.1-<4$ years, 30 (100\%) & $2.1-<4$ years, 30 (100\%) \\
\hline
\end{tabular}


Table 5 Mean and standard deviation (SD) values of the total score and the scores of each item of the Egyptian Arabic pragmatic language test (EAPLT) language ages by the Modified Pre-school Language Scale-4, Arabic version and comparison between their values among the 2 studied groups

\begin{tabular}{|c|c|c|c|c|c|}
\hline \multirow{2}{*}{\multicolumn{2}{|c|}{ EAPLT items }} & \multirow[t]{2}{*}{$\begin{array}{l}\text { Test } \\
\text { score }\end{array}$} & \multirow{2}{*}{$\begin{array}{l}\text { Group I } \\
(n=30) \\
\text { Prelingual SNHL children CI before } \\
3 \text { years } \\
(\text { mean } \pm \text { SD) }\end{array}$} & \multirow{2}{*}{$\begin{array}{l}\text { Group II } \\
(n=30) \\
\text { Prelingual SNHL children } \mathrm{Cl} \text { after } \\
3 \text { years } \\
(\text { mean } \pm \text { SD) }\end{array}$} & \multirow[t]{2}{*}{$\begin{array}{l}p \\
\text { value }\end{array}$} \\
\hline & & & & & \\
\hline \multicolumn{2}{|c|}{ Nonverbal aspects } & 10 & $5.8 \pm 2.35$ & $5.1 \pm 1.48$ & 0.178 \\
\hline \multicolumn{2}{|c|}{ Paralinguistic aspects } & 10 & $3.7 \pm 1.91$ & $2.8 \pm 1.63$ & 0.029 \\
\hline \multicolumn{2}{|l|}{ Inference } & 13 & $0.13 \pm 0.50$ & $0.1 \pm 0.51$ & 1.00 \\
\hline \multirow[t]{2}{*}{ Narratives } & Story retelling & 32 & $9.07 \pm 5.65$ & $7.4 \pm 6.75$ & 0.305 \\
\hline & $\begin{array}{l}\text { Story retelling from } \\
\text { pictures }\end{array}$ & 16 & $4.1 \pm 2.40$ & $3.5 \pm 2.92$ & 0.390 \\
\hline \multicolumn{2}{|c|}{ Comprehension of "WH" questions } & 25 & $7.4 \pm 4.83$ & $5.1 \pm 4.13$ & 0.054 \\
\hline \multicolumn{2}{|c|}{ Pragmatic functions } & 6 & $1.6 \pm 1.162$ & $1.1 \pm 0.63$ & 0.055 \\
\hline \multicolumn{2}{|c|}{ Pragmatic factors } & 15 & $3.6 \pm 2.72$ & $2.3 \pm 2.15$ & 0.013 \\
\hline \multicolumn{2}{|l|}{ Total score } & 127 & $35.7 \pm 19.67$ & $27.9 \pm 18.07$ & 0.100 \\
\hline
\end{tabular}

Paired $t$ test; $p$ value is significant at $<0.05$

skills was unexpected. This is because children who had CI before the age of 3 years were supposed to have better language development and social interaction than children who had CI lately after the age of 3 years. The explanation is that the children with CI who participated in this study in either of the two groups showed no difference in their language abilities. They had almost the same receptive, expressive, and total language scores and ages. Also, they received almost the same duration of language rehabilitation therapy since the hearingimpairment was discovered. This study revealed that pragmatic language development is strongly related to the duration of language rehabilitation received and the degree of language development and is not related to the age of CI. Therefore, the longer duration of language rehabilitation allows better language development and in consequence allows the development of good pragmatic language abilities. Another explanation is that about 75\% of the participated children (19 children in 227 group I, 26 children in group II) were fitted with bilateral HAs before the age of CI. The findings of this study added conflicts about the benefits of early cochlear implantation. Despite that, surgeons suggest that CI should be performed early (perhaps under the age of 1 year), literature still has incomplete evidence regarding the benefit of early CI on language development generally and pragmatic language development specifically. A systematic review by Bruijnzeel et al. [12] indicates that early cochlear implantation (under the age of 1-2 years) is beneficial when considering speech perception and production, and auditory performance with conflicting evidence regards the benefits of early $\mathrm{CI}$ on all speech and language outcome measures. Cochlear implantation provides the hearing-impaired children dramatic and continuous improvement of the auditory and speech abilities; however, the age at implantation played a considerably smaller role in the improvement of hearing, language, and speech abilities [24]. Several studies indicated that the age at implantation was not significantly associated with linguistic progress and the long-term language development did not differ between children who cochlear implanted in the first year [21] and did not differ between children implanted before the age of 3 years and those implanted between 3 and 6 years of age $[25,26]$.

Throughout this study, although all children with CI who participated in this study have delayed pragmatic language development, it was found that their pragmatic language develops with their age. Unlike other language modalities such as syntax, semantics, and phonology that most of the typically developed children master its rules by the age of 5 years. Pragmatic language skills start to be acquired at a very early age but are refined and developed over time by permitting the child to have experience in different social interactions. For those children with HI, even so, the pragmatic language develops with the increase of age, the acquisition of language is more crucial. This study revealed that pragmatic language development is positively correlated to the language age (receptive, expressive, total language age) of the children with $\mathrm{CI}$ in the two studied groups. The relationship between linguistic and pragmatic skills was reported by several studies that confirmed that children with 
Table 6 Comparison of the Egyptian Arabic Pragmatic Language test (EAPLT) results in conversational skills between the 2 studied groups

\begin{tabular}{|c|c|c|c|}
\hline & \multirow{2}{*}{$\begin{array}{l}\text { Group I } \\
(n=30) \\
\text { Prelingual SNHL children CI before } 3 \text { years }\end{array}$} & $\begin{array}{l}\text { Group II } \\
(n=30)\end{array}$ & $p$ value \\
\hline & & \multicolumn{2}{|l|}{ Prelingual SNHL children $\mathrm{Cl}$ after 3 years } \\
\hline \multicolumn{3}{|l|}{ Child attention } & 0.526 \\
\hline - Bad & $2(6.7 \%)$ & $2(6.7 \%)$ & \\
\hline - Fair & $12(40 \%)$ & $16(53.3)$ & \\
\hline - Good & $16(53.3)$ & $12(40 \%)$ & \\
\hline \multicolumn{3}{|c|}{ Topic introduction } & - \\
\hline - Yes & $0(0 \%)$ & $0(0 \%)$ & \\
\hline • No & $30(100 \%)$ & $30(100 \%)$ & \\
\hline \multicolumn{3}{|l|}{ Topic change } & - \\
\hline - Yes & $0(0 \%)$ & $0(0 \%)$ & \\
\hline • No & $30(100 \%)$ & $30(100 \%)$ & \\
\hline \multicolumn{3}{|l|}{ Turn-taking } & 0.317 \\
\hline$\cdot<3$ & $20(66.7 \%)$ & $28(93.3 \%)$ & \\
\hline$\cdot 3$ & $0(0 \%)$ & $0(0 \%)$ & \\
\hline$\cdot>3$ & $10(33.3 \%)$ & $2(6.7 \%)$ & \\
\hline \multicolumn{3}{|l|}{ Gap } & 0.395 \\
\hline • No & $4(13.3 \%)$ & $14(46.7 \%)$ & \\
\hline$\cdot \leq 1 \mathrm{~s}$ & $2(6.7)$ & $0(0 \%)$ & \\
\hline$\cdot>1 \mathrm{~s}$ & $24(80 \%)$ & $16(53.3)$ & \\
\hline \multicolumn{3}{|l|}{ Overlap } & 1.000 \\
\hline • No & $4(13.3 \%)$ & $16(53.3)$ & \\
\hline - Inappropriate & $4(13.3 \%)$ & $14(46.7 \%)$ & \\
\hline - Appropriate & $22(73.3 \%)$ & $0(0 \%)$ & \\
\hline \multicolumn{3}{|c|}{ Ask clarification request } & 0.134 \\
\hline - None & $8(26.7 \%)$ & $18(60 \%)$ & \\
\hline - Inappropriate & $16(53.3)$ & $12(40 \%)$ & \\
\hline - Appropriate & $6(20 \%)$ & $0(0 \%)$ & \\
\hline \multicolumn{3}{|c|}{ Response to clarification requests } & 0.254 \\
\hline - None & $6(20 \%)$ & $12(40 \%)$ & \\
\hline - Inappropriate & $18(60 \%)$ & $18(60 \%)$ & \\
\hline - Appropriate & $6(20 \%)$ & $0(0 \%)$ & \\
\hline Self-repair & 0.73 & & 0.208 \\
\hline - Yes & $12(40 \%)$ & $22(73.3 \%)$ & \\
\hline • No & $18(60 \%)$ & $8(26.7 \%)$ & \\
\hline \multicolumn{3}{|c|}{ Conversational breakdown } & 0.329 \\
\hline - Yes & $8(26.7 \%)$ & $12(40 \%)$ & \\
\hline • No & $22(73.3 \%)$ & $18(60 \%)$ & \\
\hline \multicolumn{3}{|c|}{ Request to end conversation } & 0.272 \\
\hline - Yes & $4(13.3 \%)$ & $8(26.7 \%)$ & \\
\hline - No & 26 (86.7\%) & 22 (73.3\%) & \\
\hline
\end{tabular}

Values are number (\%). Paired $t$ test; $p$ value is significant at $<0.05$ 
Table 7 Pearson Correlation between the total score of the Egyptian Arabic Pragmatic language test (EAPLT) and the chronological age, the age at time of $\mathrm{Cl}$, the duration of the received language rehabilitation and the scores of the modified PLS-4 (Arabic version) among the participated children in the 2 studied groups

\begin{tabular}{|c|c|c|c|c|c|}
\hline \multicolumn{6}{|l|}{ Total score of EAPLT } \\
\hline \multirow{3}{*}{\multicolumn{2}{|c|}{ Pearson correlation }} & \multirow{2}{*}{\multicolumn{2}{|c|}{$\begin{array}{l}\text { Group I } \\
(n=30)\end{array} \begin{array}{l}\text { Prelingual SNHL children CI before } \\
3 \text { years }\end{array}$}} & \multirow{2}{*}{\multicolumn{2}{|c|}{$\begin{array}{l}\text { Group II } \\
(n=30) \\
\begin{array}{l}\text { Prelingual SNHL children } \mathrm{Cl} \text { after } \\
3 \text { years }\end{array}\end{array}$}} \\
\hline & & & & & \\
\hline & & $r$ & $p$ value & $r$ & $p$ value \\
\hline \multicolumn{2}{|l|}{ The chronological age } & $0.650^{* *}$ & $0.000^{* *}$ & $0.492^{* *}$ & 0.006 \\
\hline \multicolumn{2}{|l|}{ Age at time of implantation } & -0.136 & 0.474 & -0.108 & 0.570 \\
\hline \multicolumn{2}{|c|}{ Age at time of starting language rehabilitation } & -0.178 & 0.346 & -0.257 & 0.170 \\
\hline \multicolumn{2}{|c|}{ Duration of the received language rehabilitation } & $0.725^{*}$ & $0.000^{* *}$ & $0.520^{*}$ & $0.003^{* *}$ \\
\hline \multirow[t]{3}{*}{ The modified PLS-4, Arabic version } & Receptive language age & $0.891^{*}$ & $0.000^{* *}$ & $0.753^{*}$ & $0.000^{* *}$ \\
\hline & Expressive language age & $0.913^{*}$ & $0.000^{* *}$ & $0.807^{*}$ & $0.000^{* *}$ \\
\hline & Total language age & $0.927^{*}$ & $0.000^{* *}$ & $0.785^{*}$ & $0.000^{* *}$ \\
\hline
\end{tabular}

*Pearson correlation; $r$ indicates significant correlation at $0.5,{ }^{* *} p$ value is significant at $<0.01$

the greatest delay in lexical skills (i.e., vocabulary size) showed the greatest delays in pragmatic skills $[8,27,28]$.

Finally, cochlear implantation either early or late could improve the ability to develop intelligible speech and better hearing for most children with hearing impairment but does not appear to aid so much in successful pragmatic language development. Hearing-impaired children with either CIs or HAs tend to acquire pragmatic skills much more slowly even with intervention strategies that targeted language therapy as reported by Goberis et al. [29]. The severe difficulties faced by the hearing-impaired children in their early social experiences and interaction mediated by their delayed language affect greatly their pragmatic language development. More than $95 \%$ of parents who have a hearingimpaired child have normal hearing, and most people in the hearing-impaired child's environment also have normal hearing and use spoken language as their mode of communication. Hearing-impaired children either with HAs or CI struggle to communicate with their hearing parents resulting in frustration on the part of both the parents and the child. These findings agree with Dammeyer [20] who found that these delays may be partially explained by considering parent-child interactions. Likewise, some studies have reported that very often hearing parents of deaf children tend to be more controlling in their interactions with their children, compared with deaf or hearing parents of deaf and hearing children, respectively [26, 27] and that after controlling the effects of non-verbal intelligence and parents' educational level, children who were cochlear implanted at young ages had higher scores on all language tests than children who were implanted at older ages [30]. Pragmatic delays in children with CI suggest that early interventions for improving pragmatic skills are recommended even in very young children with CI. Pragmatic scores can provide important supplemental information for decisions regarding the appropriate age of CI [14].

\section{Conclusions}

The pragmatic language of cochlear implanted children who have been implanted either before or after 3 years old is greatly affected. The age of implantation has no impact on pragmatic language development. The prelingual children with $\mathrm{CI}$ are susceptible to delays in the pragmatic language development that is primarily related to the age of those children and their language abilities, besides their experience in social interactions. These results should be considered in their rehabilitative plan and advocate the importance of early incorporation of pragmatic behaviors into their intervention programs.

\section{Abbreviations}

Cl: Cochlear implantation (Cl); Cls: Cochlear implants (Cls);

SNHL: Sensorineural hearing loss (SNHL); HAs: Hearing aids (HAs); PLS-4: The Modified Preschool Language Scale-4th edition (PLS-4), the Arabic version; EAPLT: The Standardized Egyptian Arabic Pragmatic Language Test

\section{Acknowledgements}

Not applicable

\section{Authors' contributions}

DFM collected independently the study data from the participated selected children. MK and RMS analyzed the collected data and interpreted these data. MK was a major contributor in writing the manuscript. All the authors read and approved the final manuscript.

\section{Funding}

The authors declare that this study did not receive any funds.

Availability of data and materials

The datasets used and/or analyzed during the current study are available from the corresponding author on reasonable request. 


\section{Declarations}

\section{Ethics approval and consent to participate}

Informed written consent was obtained from all parents of the children before enrollment in the study and the study protocol has been approved by the Ain Shams Institute's Ethical Committee of Human Research in April 2019. The committee's reference number is not available.

\section{Consent for publication}

Not applicable.

\section{Competing interests}

The authors declare that they have no competing interests.

\section{Author details}

'Unit of Phoniatrics, Otorhinolaryngology Department, Faculty of Medicine, Ain Shams University, Abbassia, Lotfy Elsayed Street, Cairo 11566, Egypt ${ }^{2}$ Phoniatrics Unit, Otorhinolaryngology Department, EgyptAir Hospital, Cairo, Egypt.

Received: 26 November 2020 Accepted: 18 March 2021

Published online: 01 April 2021

\section{References}

1. Niparko JK, Tobey EA, Thal DJ, Eisenberg LS, Wang NY, Quittner AL, Fink NE (2010) Spoken language development in children following cochlear implantation. JAMA 303(15):1498-1506

2. Moore JA, Teagle Holly FB (2002) An introduction to cochlear implant technology, activation, and programming. Articles in Language, Speech, and Hearing Services in Schools. https://doi.org/10.1044/0161-1461(2002/013).

3. Spencer L, Tomblin JB (2009) Spoken language development in oral preschool children with permanent childhood deafness. J Deaf Stud Deaf Educ 14(2):205-217. https://doi.org/10.1093/deafed/enn034

4. McConkey R, Nixon T, Donaghy E, Mulhern D (2004) The characteristics of children with a disability looked after away from home and their future service needs. Br J Soc Work 34:561-576

5. Ruben R (1997) A Time Frame of Critical/Sensitive Periods of Language Development. Acta Otolaryngol. https://doi.org/10.3109/0001648970911 7769

6. Jeanes RC, Nienhuys TG, Rickards FW (2000) The pragmatic skills of profoundly deaf children. J Deaf Stud Deaf Educ. https://doi.org/10.1093/ deafed/5.3.237

7. Guest HE (2013) Pragmatics social communication: children with hearing loss in early 315 childhood settings [Honors Thesis]. School of Communication Science and Disorders, 316 Florida State University. Florida, United States of America. Available via Florida State University Digital Library. http://purl.flvc.org/fsu/fd/FSU migr uhm-0208. Accessed 15 Jan 2021.

8. Most T, Shina-August E, Meilijson S (2010) Pragmatic abilities of children with hearing loss using cochlear implants or hearing aids compared to hearing children. J Deaf Stud Deaf Educ. https://doi.org/10.1093/deafed/ enq032

9. Lederberg AR, Everhart VS (2000) Conversation between deaf children and their hearing mothers: pragmatic dialogic characteristics. J Deaf Stud Deaf Educ 5:303-322

10. Rinaldi P, Baruffaldi F, Burdo S, Caselli MC (2013) Linguistic and pragmatic skills in toddlers with a cochlear implant. Int J Lang Commun Disord. https://doi.org/10.1111/14606984.12046

11. Tomblin JB, Barker BA, Spencer $L J$ et al (2005) The effect of age at cochlear implant initial stimulation on expressive language growth in infants and toddlers. J Speech Lang Hear Res 48:853-867

12. Bruijnzeel H, Ziylan F, Stegeman I, Topsakal V, Grolman W (2016) A Systematic Review to Define the Speech and Language Benefit of Early (< 12 Months) Pediatric Cochlear Implantation. Audiol Neurootol. https://doi. org/10.1159/000443363

13. May-Mederake B (2012) Early intervention and assessment of speech and language development in young children with cochlear implants. Int J Pediatr Otorhinolaryngol. https://doi.org/10.1016/j.ijporl.2012.02.051

14. Socher M, Lyxell B, Ellis R, Gärskog M, Hedström I, Wass M (2019) Pragmatic language skills: a comparison of children with cochlear implants and children without hearing loss. Front Psychol. https://doi.org/10.3389/fpsyg.2 019.02243

15. Hamid AA, Elshazly M, Eldessouky T, Ghaffar HA, Radwan A, Monem AA (2015) Predictors of language and auditory skills in Egyptian children with a cochlear implant. Egypt J Otolaryngol. https://doi.org/10.4103/1012-5574.1 61605

16. Hanoura MA (2002) Stanford-Binet intelligence test: Arabic version, 5th edn. Anglo Press, Egypt

17. Kotby MN, Bassiouny S, Rifaie N, Hassan N, Sayed A (1995) Protocol of communicative assessment of cochlear implant patients. In: Kotby MN (ed) Proceedings of XXIII World Congress of the IALP (pp. 431 - 433). IAPL: Cairo (Egypt)

18. Abou Hassiba A, El Sady S, Elshobary A, Gamal Eldin N, Ibrahiem A, Oweys A (2011) Standardization, translation and modification of the Preschool Language Scale - 4. Dissertation, Faculty of Medicine, Ain Shams University, Cairo, Egypt

19. Khodeir MS, Hegazi MA, Saleh MM (2017) Development and Standardization of a Test for Pragmatic Language Skills in Egyptian Arabic: The Egyptian Arabic Pragmatic Language Test (EAPLT). Folia Phoniatr Logop. https://doi. org/10.1159/000485656

20. Dammeyer J (2012) A longitudinal study of pragmatic language development in three children with cochlear implants. Deaf Educ Int. https://doi.org/10.1179/14643154

21. Szagun G, Stumper B (2012) Age or Experience? The influence of age at implantation, social, and linguistic environment on language development in children with cochlear implants. J Speech Lang Hear Res 55:1640-1654

22. Fitzpatrick EM, Johnson E, Durieux-Smith A (2011) Exploring factors that affect the age of cochlear implantation in children. Int J Pediatr Otorhinolaryngol. https://doi.org/10.1016/j.jporl.2011.05.018

23. Mood D, Szarkowski A, Brice PJ, Wiley S (2020) Relational Factors in Pragmatic Skill Development: Deaf and Hard of Hearing Infants and Toddlers. Pediatrics. https://doi.org/10.1542/peds.2020-0242D

24. Guo Q, Lyu J, Kong Y, Xu T, Dong R, Qi B, Wang S, Chen X (2020) The development of auditory performance and speech perception in $\mathrm{Cl}$ children after long-period follow up. Am J Otolaryngol. https://doi.org/10.1016/j.a mjoto.2020.102466

25. Rinaldi $P$, Baruffaldi F, Burdo S, Caselli MC (2013) Linguistic and pragmatic skills in toddlers with cochlear implant. Int J Lang Commun Disord 48(6): 715-725. https://doi.org/10.1179/146701010X12671177989110

26. Brackett D, Sara CV (1998) Communication outcomes related to early implantation. Am J Otol 19(4):453-460

27. Bebko JM, Calderon R, Treder R (2003) The Language Proficiency Profile-2: Assessment of the Global Communication Skills of Deaf Children Across Languages and Modalities of Expression. J Deaf Stud Deaf Educ. https://doi. org/10.1093/deafed/eng034

28. Lichtig I, Couto MI, Mecca FF, Hartley S, Wirz S, Woll B (2011) Assessing deaf and hearing children's communication in Brazil. J Commun Disord. https:// doi.org/10.1016/j.jcomdis.2010.11.002

29. Goberis D, Beams D, Dalpes M, Abrisch A, Baca R, Yoshinaga-Itano C (2012) The missing link in the language development of deaf and hard of hearing children: pragmatic language development. Semin Speech Lang. https://doi. org/10.1055/s-0032-1326916

30. Geers AE, Moog JS, Biedenstein J, Brenner C, Hayes H (2009) Spoken language scores of children using cochlear implants compared to hearing age-mates at school entry. J Deaf Stud Deaf Educ. https://doi.org/10.1093/ deafed/enn046

\section{Publisher's Note}

Springer Nature remains neutral with regard to jurisdictional claims in published maps and institutional affiliations. 